\title{
Analysis of pain and free cortisol of newborns in intensive therapy with therapeutic procedures
}

\author{
Análise da dor e do cortisol livre em recém-nascidos em terapia intensiva com procedimentos \\ terapêuticos
}

Cibele Thomé da Cruz Rebelato', Eniva Miladi Fernandes Stumm²

DOI 10.5935/2595-0118.20190029

\section{ABSTRACT}

BACKGROUND AND OBJECTIVES: Newborns at high risk in the intensive care unit are exposed to painful, repetitive and prolonged procedures that may be related to changes in brain development and behavioral abnormalities. The objective of this study was to relate pain and free cortisol of premature newborns undergoing therapeutic procedures in intensive care units.

METHODS: A quantitative, descriptive, cross-sectional study conducted with 32 premature newborns submitted to venipuncture, who were evaluated for pain and stress related to assisted ventilation; sedatives, prenatal corticoid, type of venipuncture, site, and the number of attempts.

RESULTS: Preterm newborns undergoing invasive ventilation had a predominance of moderate pain in 12 (37.5\%) and cortisol increase in $14(43.8 \%)$ of them. Venipuncture triggered moderate and intense pain, 10 (31.3\%), and in 17 (53.1) the cortisol levels increased. More than half was due to peripherally inserted central catheter placement, so that 10 (43.8) had moderate pain. The results of the research suggest that the exposure of newborns to invasive procedures is stressful, especially when repeated several times.

CONCLUSION: Repeated venous puncture associated with therapeutic procedures intensified pain and altered cortisol, causing stress in premature newborns.

Keywords: Intensive care unit, Nursing, Pain measurement, Physiological stress, Premature newborn.

Cibele Thomé da Cruz Rebelato - Dhttps://orcid.org/0000-0002-1875-8309;

Eniva Miladi Fernandes Stumm - Dhttps://orcid.org/0000-0001-6169-0453.

1. Associação Hospital de Caridade de Ijuí, Unidade de Terapia Intensiva Neonatal, Ijuí, RS, Brasil.

2. Universidade Regional do Noroeste do Estado do Rio Grande do Sul, Departamento de Enfermagem, Ciências da Vida, Programa de Pós-Graduaçẩo Scricto Sensu, Ijuí, RS, Brasil.

Submitted on November 05, 2018.

Accepted for publication on April 29, 2019.

Conflict of interests: none - Sponsoring sources: none.

Correspondence to

Rua do Comércio, 3000 - Bairro Universitário

98700-000 Ijuí, RS, Brasil.

E-mail: cibelethome@bol.com.br

(C) Sociedade Brasileira para o Estudo da Dor

\section{RESUMO}

JUSTIFICATIVA E OBJETIVOS: Os recém-nascidos de alto risco em unidade de terapia intensiva, são expostos a procedimentos dolorosos, repetitivos e prolongados que podem estar relacionados a alteraçóes no desenvolvimento do cérebro e anomalias comportamentais. O objetivo deste estudo foi relacionar a dor e o cortisol livre de recém-nascidos prematuros, com procedimentos terapêuticos instituídos em terapia intensiva.

MÉTODOS: Pesquisa quantitativa, descritiva, transversal, realizada com 32 recém-nascidos prematuros submetidos à punção venosa, que foram avaliados quanto à dor e estresse relacionado à ventilação assistida; sedativos, corticoide no pré-natal, tipo de punção venosa, local e número de tentativas.

RESULTADOS: Recém-nascidos prematuros submetidos à ventilação invasiva apresentaram predomínio de dor moderada em $12(37,5 \%)$ e aumento de cortisol em 14 (43,8\%) deles. A punção venosa desencadeou dor moderada e intensa, 10 (31,3\%) e em $17(53,1)$ ocorreu aumento do nível de cortisol. Mais da metade ocorreu para passagem de cateter central de inserçáo periférica, de modo que $10(43,8)$ tiveram dor moderada. Os resultados da investigação, sugerem que a exposição dos recém-nascidos a procedimentos invasivos é estressante, especialmente quando repetido várias vezes.

CONCLUSÃO: A punção venosa repetida associada a procedimentos terapêuticos intensificou a dor e alterou o cortisol, o que implica em estresse ao recém-nascido prematuro.

Descritores: Enfermagem, Estresse fisiológico, Mensuração da dor, Recém-nascido prematuro, Unidades de terapia intensiva.

\section{INTRODUCTION}

The high-risk newborn (NB) in the neonatal intensive care unit (NICU) is exposed to painful procedures, repeated, prolonged events, related to a deficiency of brain development and behavioral abnormalities ${ }^{1}$.

Neonatal pain may trigger stress. In addition, the stress caused by the NICU environment may result in higher plasma cortisol levels than surgery. Increased concentrations of stress-related hormones in sick and preterm NB is associated with an increased risk of mortality ${ }^{2}$. Therefore, it is incumbent on nurses to use pharmacological and non-pharmacological measures in order to prevent and reduce pain and neonatal stress.

In a research study in California with 237 neonatal nurses, 81\% of them reported the use of pain assessment instruments, $83 \%$ 
felt confident with pharmacological measures, and 79\% with nonpharmacological ${ }^{3}$. The authors pointed out that pain management was correlated with adequate training and pain assessment instruments from care protocols.

Cortisol is a glucocorticoid that exerts physiological effects on the metabolism of carbohydrates, proteins, and fatty acids and plays an important role in the physiological response to stress ${ }^{4,5}$. Cortisol also has negative feedback effects on the hypothalamus to reduce the formation of corticotrophin-releasing hormone, and on the anterior pituitary, decreasing the formation of the adrenocorticotrophic hormone.

On the other hand, stress has a physiological effect on the secretion of adrenocorticotrophic hormone, triggering, in minutes, an increase of up to 20 times in the secretion of cortisol ${ }^{6}$.

In this sense, a research quantified the severity of common stressors for premature infants ${ }^{7}$. Seventeen physicians and 130 nurses working in NICU participated in the research, and classified the severity of the perceived stress of 44 acute events (peripheral venous access, peripheral arterial access, central venous access, ventilation, nutrition, medical procedures, surgery, radiology and others) and 24 life conditions, characterized as chronic (receiving intranasal oxygen due to repeated bronchopulmonary dysplasia and infection), in preterm infants with gestational age of 28, 28 to 32 and after 32 weeks. Physicians and nurses have realized that almost all events are stressful for NB to some degree and become equally stressful over the ages.

Thus, this article aimed to correlate pain and cortisol free of preterm NB with therapeutic procedures instituted in NICUs, in order to assess the occurrence of stress in these NB.

\section{METHODS}

A quantitative, descriptive, cross-sectional study conducted at a NICU of a philanthropic hospital institution, size IV, in the northwest of the State of Rio Grande do Sul. This unit provides eight neonatal beds of the Unified Health System (SUS), with a multiprofessional team, composed of pediatricians, nurses, nursing technicians, physiotherapists, and speech therapists.

The calculation of the sample was for convenience. 32 preterm NB hospitalized at the NICU between March and October 2016 participated in the study and met the included inclusion criteria: being premature, not having undergone another painful procedure one hour before venipuncture and signing the Free Informed Consent Term (FICT).

Data collection was performed through a research protocol composed of a form with identification data, sociodemographic, and clinical data of the NB obtained directly from their medical records. The particular form contemplates the variables: assisted ventilation; sedatives, prenatal corticoid, type of venipuncture, site, and the number of attempts. Pain assessment was performed with the Neonatal Infant Pain Scale (NIPS), and cortisol, with diuresis samples from the NB.

The diuresis samples of the NB participating in the research were obtained by collector device, or directly from the bladder catheter after being submitted to venipuncture for peripheral access, or a peripherally inserted central catheter (PICC) insertion. The first diuresis sample was obtained after exposure of the NB to this procedure. The urine samples were kept without a preservative in a refrigerator at 2 to $8^{\circ} \mathrm{C}$ and then sent to the Laboratory of Clinical Analysis and for analysis by electrochemiluminescence. $11 \mathrm{NB}$, in whom the diuresis samples collected were insufficient for cortisol analysis, were excluded from the research.

All the ethical precepts governing human research (Resolution 466/12 of the Ministry of Health) ${ }^{8}$ were respected. The study was approved by the Ethics and Research Committee, in December 2015, CAAE no 50914015.8.0000.5350, opinion number 1.354.128.

\section{Statistical analysis}

Data analysis was performed with descriptive statistics, involving position measurements (lower limit, upper limit, quartile 1 , median, quartile 3 and mean) and of dispersion (standard deviation and range), and Student's t-test, with the use of SPSS 17.0 software.

\section{RESULTS}

Table 1 shows that invasive ventilation, which routinely preterm NB undergo, triggers a predominance of moderate pain in $37.5 \%$. In the NBs with continuous positive airway pressure (CPAP), moderate or severe pain occurred in $9.4 \%$ of the sample and severe pain occurred in $15.6 \%$ of the cases in the NB in the hood.

Regarding the puncture site, in the upper limbs, $68.8 \%$ of the $\mathrm{NB}$ received the largest number of punctures and presented moderate and severe pain at the same frequency, which was 31.3\%. Regarding the purpose of the puncture, more than half occurred for the passage of PICC, so that $10 \mathrm{NB}(43.8 \%)$ had moderate pain. Still concerning venipuncture, in terms of the number of attempts, infants submitted to a single venipuncture presented moderate pain in $12.5 \%$ and severe pain in $9.4 \%$ of the sample. Regarding invasive ventilation, table 2 shows an increase of cortisol in $43.8 \%$ of the NB. $12.5 \%$ of the newborns in CPAP and $9.4 \%$ of those in the hood had alterations in cortisol levels.

The highest number of punctures was in UL in $68.8 \%$ of NB, and $53.1 \%$ presented increased cortisol level. Regarding the purpose of the puncture, more than half occurred for the passage of PICC, so that in $43.8 \%$ there was an increase in free cortisol levels. Also, regarding venipuncture in terms of number of attempts, $25 \%$ of NB submitted to a single venipuncture showed alterations in the cortisol level.

Table 3 presents the descriptive measures of cortisol according to some variables, where it is observed in each of them that the lower limbs (LL) and the lower limbs (UL) have a large range. Also, a broader standard deviation is observed in relation to the mean. It is observed that there is a significant difference only between the means of cortisol levels with variable "type of puncture." Figure 1 shows the position measurements (LL, UL, quartile 1 , median, and quartile 3), where four cases of outliers are identified, in which the values of cortisol levels were very high. These preterm newborns (PTNB) are considered to be the most stressed. 
Table 1. Pain analysis, according to variables of newborns in the neonatal intensive care unit. March-October 2016

\begin{tabular}{|c|c|c|c|c|c|c|}
\hline \multirow[t]{2}{*}{ Variables } & \multirow[b]{2}{*}{ Categories } & \multicolumn{4}{|c|}{ Puncture pain assessment } & \multirow{2}{*}{$\begin{array}{l}\text { Total } \\
\text { n (\%) }\end{array}$} \\
\hline & & $\begin{array}{c}\text { No pain } \\
\mathrm{n}(\%)\end{array}$ & $\begin{array}{l}\text { Mild pain } \\
\mathrm{n}(\%)\end{array}$ & $\begin{array}{c}\text { Moderate pain } \\
\mathrm{n}(\%)\end{array}$ & $\begin{array}{c}\text { Severe pain } \\
\mathrm{n}(\%)\end{array}$ & \\
\hline \multirow[t]{4}{*}{ Ventilation } & Invasive ventilation & $1(3.1)$ & $1(3.1)$ & $12(37.5)$ & $4(12.5)$ & $18(56.3)$ \\
\hline & Nasal CPAP & - & - & $3(9.4)$ & $3(9.4)$ & $6(18.8)$ \\
\hline & Hood & - & - & $1(3.1)$ & $5(15.6)$ & $6(18.8)$ \\
\hline & Ambient air & - & - & $1(3.1)$ & $1(3.1)$ & $2(6.3)$ \\
\hline \multirow{4}{*}{ Puncture site } & UL & $1(3.1)$ & $1(3.1)$ & 10(31.3) & 10(31.3) & $22(68.8)$ \\
\hline & LL & - & - & $4(12.5)$ & $1(3.1)$ & $5(15.6)$ \\
\hline & Cephalic region, UL and LL & - & - & - & $2(6.3)$ & $2(6.3)$ \\
\hline & UL and LL & - & - & $2(6.3)$ & - & $2(6.3)$ \\
\hline Type of puncture & Passage of PICC & $1(3.1)$ & - & $10(31.3)$ & $7(21.9)$ & $18(56.3)$ \\
\hline \multirow{5}{*}{ Number of attempts } & Three & - & - & $3(9.4)$ & $2(6.3)$ & $5(15.6)$ \\
\hline & Four & - & - & $3(9.4)$ & $2(6.3)$ & $5(15.6)$ \\
\hline & Six & - & - & $3(9.4)$ & $1(3.1)$ & $4(12.5)$ \\
\hline & Eight & - & - & - & $1(3.1)$ & $1(3.1)$ \\
\hline & Nine & - & - & - & $1(3.1)$ & $1(3.1)$ \\
\hline Total & & $1(3,1)$ & $1(3.1)$ & $17(53.1)$ & $13(40.6)$ & $32(100)$ \\
\hline
\end{tabular}

$\overline{\mathrm{CPAP}}=$ continuous positive airway pressure; UL = upper limbs, $\mathrm{LL}=$ lower limbs; PICC = peripherally inserted central catheter.

Table 2. Cortisol analysis, according to the variables of newborns in the neonatal intensive care unit. March-October/2016

\begin{tabular}{|c|c|c|c|c|}
\hline \multirow[t]{2}{*}{ Variables } & \multirow[b]{2}{*}{ Categories } & \multicolumn{2}{|l|}{ Cortisol } & \multirow[t]{2}{*}{ Total } \\
\hline & & $\begin{array}{c}2 \text { to } 27 \\
\mathrm{n}(\%)\end{array}$ & $\begin{array}{c}\text { Greater than } 27 \\
\mathrm{n}(\%)\end{array}$ & \\
\hline \multirow{3}{*}{ Ventilation } & Nasal CPAP & $2(6.3)$ & $4(12.5)$ & $6(18.8)$ \\
\hline & hood & $3(9.4)$ & 3(9.4) & $6(18.8)$ \\
\hline & Ambient air & - & $2(6.3)$ & $2(6.3)$ \\
\hline \multirow{4}{*}{ Puncture site } & UL & $5(15.6)$ & $17(53.1)$ & $22(68.8)$ \\
\hline & LL & $2(6.3)$ & $3(9.4)$ & $5(15.6)$ \\
\hline & Cephalic region, UL and LL & - & $2(6.3)$ & $2(6.3)$ \\
\hline & UL and LL & $2(6.3)$ & - & $2(6.3)$ \\
\hline \multirow{6}{*}{ Number of attempts } & Two & $4(12.5)$ & $3(9.4)$ & $7(21.9)$ \\
\hline & Three & $2(6.3)$ & $3(9.4)$ & $5(15.6)$ \\
\hline & Four & $1(3.1)$ & $4(12.5)$ & $5(15.6)$ \\
\hline & Six & $1(3.1)$ & 3(9.4) & $4(12.5)$ \\
\hline & Eight & - & $1(3.1)$ & $1(3,1)$ \\
\hline & Nine & - & $1(3.1)$ & $1(3,1)$ \\
\hline Total & & $9(28.1)$ & 23 & $32(100)$ \\
\hline
\end{tabular}

CPAP = continuous positive airway pressure; UL = upper limbs, LL = lower limbs; PICC = peripherally inserted central catheter. 
Table 3. Descriptive statistics and Student $t$ test of cortisol according to the variables of the newborns. March-October/2016

\begin{tabular}{|c|c|c|c|c|c|c|c|c|c|}
\hline \multirow[t]{2}{*}{ Variables } & \multirow[t]{2}{*}{ Categories } & \multicolumn{8}{|c|}{ Cortisol } \\
\hline & & $\mathrm{n}$ & LL & UL & Range & Median & Mean & Standard deviation & $p$-value \\
\hline Gender & Female & 15 & 3.04 & 557.1 & 554.06 & 52.60 & 124.93 & 157.24 & 0.380 \\
\hline \multirow[t]{2}{*}{ Sedation } & Yes & 16 & 3.04 & 598.0 & 594.96 & 52.50 & 121.43 & 182.17 & 0.424 \\
\hline & No & 16 & 6.51 & 373.0 & 366.49 & 37.80 & 79.39 & 98.91 & \\
\hline \multirow[t]{2}{*}{ Corticoid } & Yes & 14 & 3.04 & 598.0 & 594.96 & 32.60 & 110.86 & 198.86 & 0.727 \\
\hline & No & 18 & 6.51 & 373.0 & 366.49 & 52.90 & 92.28 & 91.36 & \\
\hline \multirow{2}{*}{$\begin{array}{l}\text { Type of } \\
\text { puncture }\end{array}$} & Passage of PICC & 18 & 3.04 & 598.0 & 594.96 & 52.90 & 142.11 & 182.33 & $0.044^{*}$ \\
\hline & Peripheral venous access & 14 & 3.76 & 169.5 & 165.74 & 41.65 & 46.79 & 41.14 & \\
\hline
\end{tabular}

*There was a significant difference for $\mathrm{p}<0.05$; LL = lower limbs; UL = upper limbs; PICC = peripherally inserted central catheter.

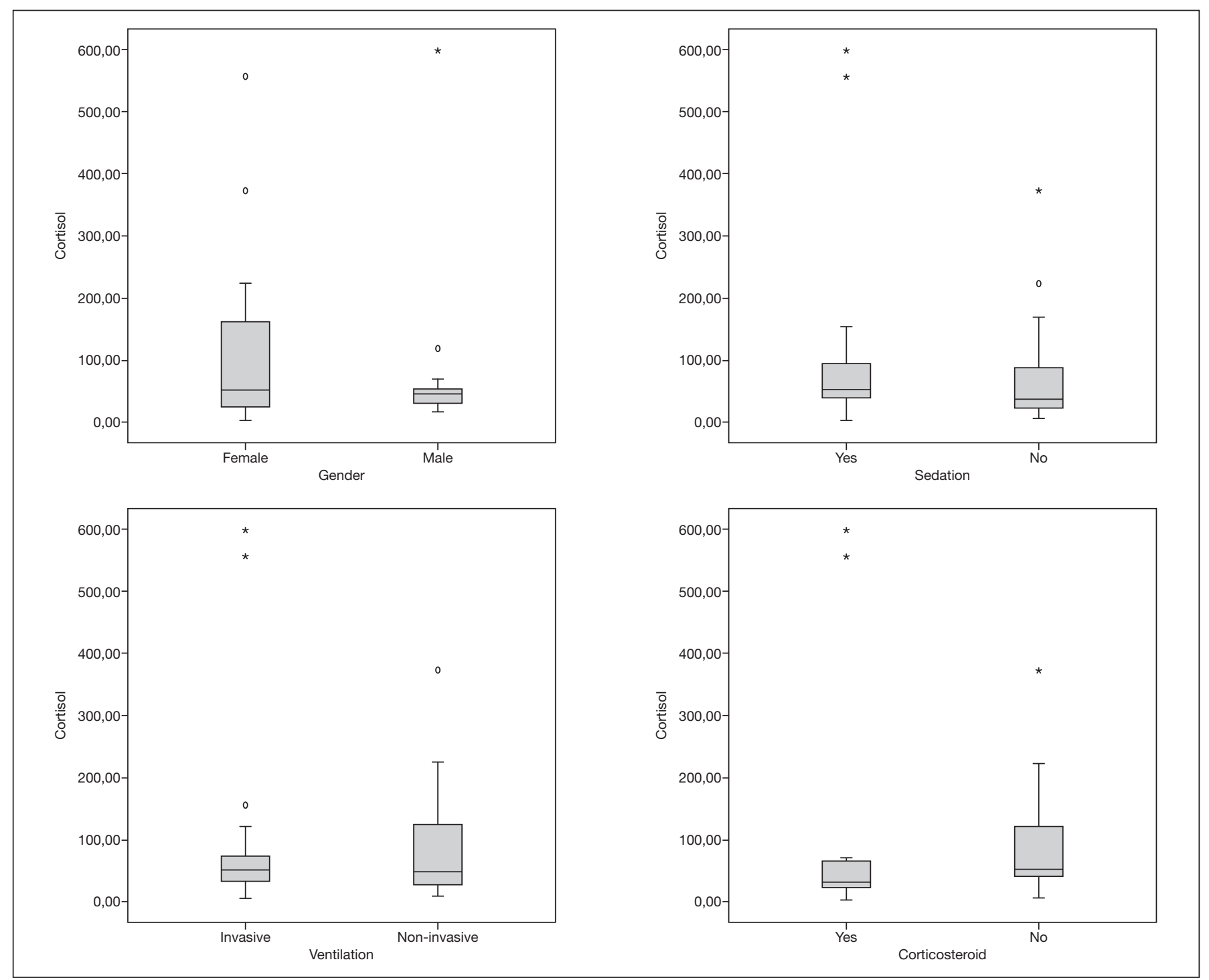

Figure 1. Cortisol position measurements according to gender, sedation, ventilation, corticosteroid, type of puncture, and number of attempts. March-October/2016 


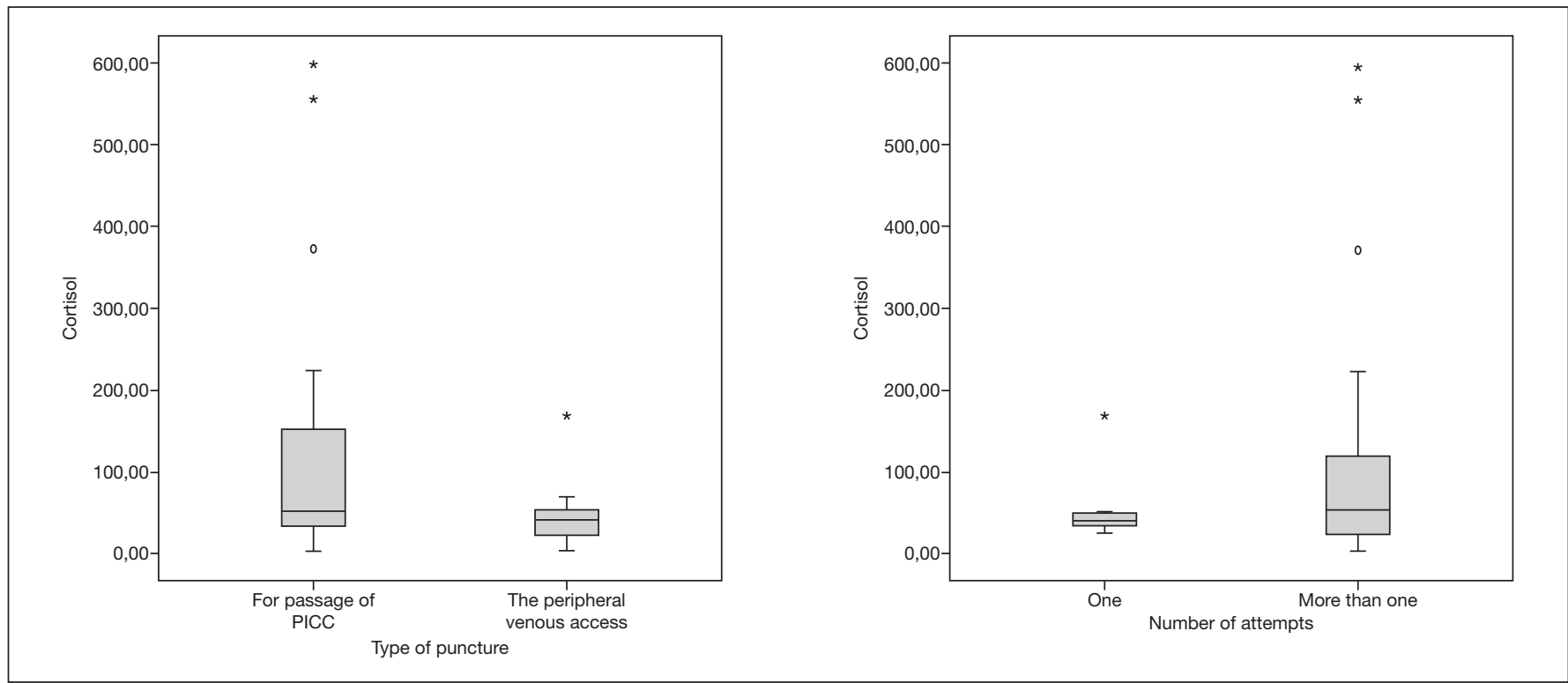

Figure 1. Cortisol position measurements according to gender, sedation, ventilation, corticoid, type of puncture, and number of attempts. March-October/2016

PICC = peripherally inserted central catheter.

Table 4. Descriptive statistics and Student's t-test of cortisol according to the variables of the newborns

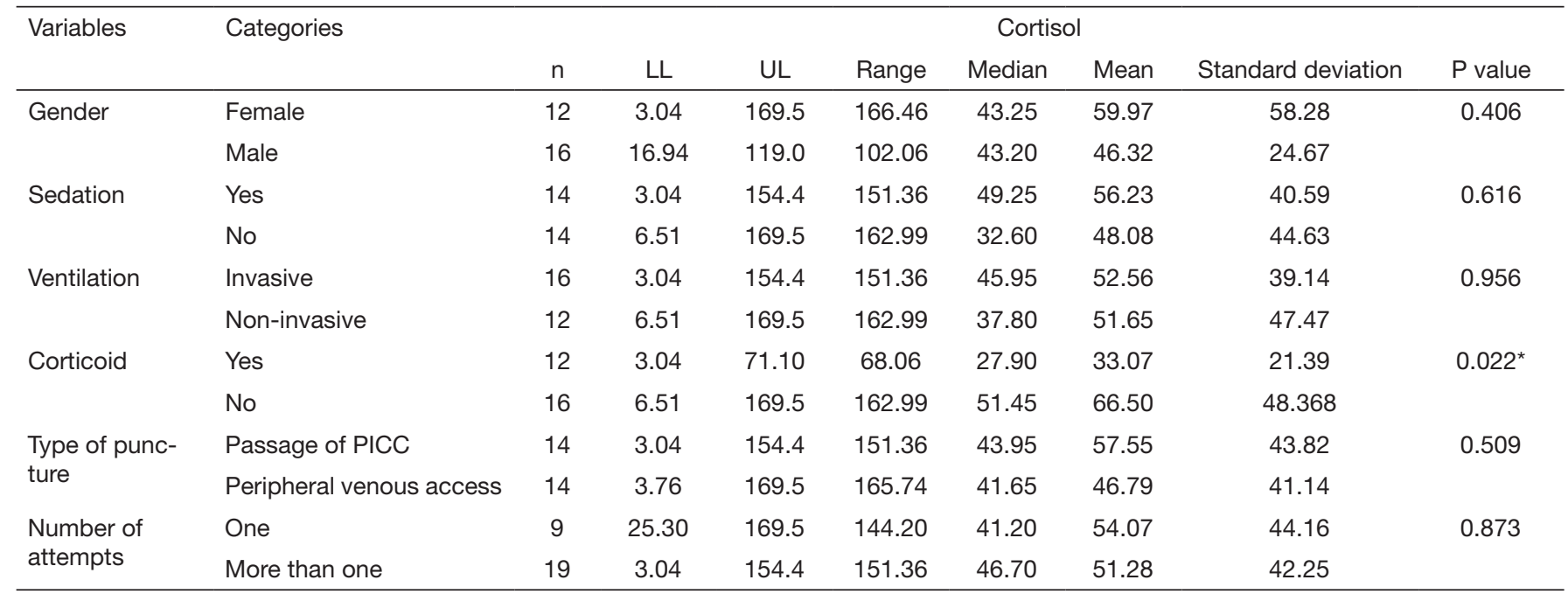

Retrospective cases of cortisol outlier $(598 ; 557.1 ; 373 ; 224.1)$; ${ }^{*}$ there was significant difference for $p<0.05$; PICC = peripherally inserted central catheter; LL = lower limit; UL = upper limit.

However, to better understand the relationships, we opted to exclude these four extreme values of cortisol, which are: 598; 557.1; 373 and 224.1. The results are shown in table 4, showing that there is a significant difference in the value of cortisol in the corticosteroid variable.

\section{DISCUSSION}

The long-term effects of untreated neonatal pain include adverse neurological outcomes, increased pain response, increased somatization, and other neuropsychological changes ${ }^{9}$. In this sense, pharmacological therapies should be used in conjunction with non-pharmacological interventions.
One research analyzed the association of pain assessment scores obtained through re-assessment, according to the Joint Commission (JC), with painful events and analgesic use in 196 premature infants on mechanical ventilation. In general, $2 \%$ of the pain scores suggested the presence of pain, $0.1 \%$ of the pain scores were associated with analgesia. Ventilated NB who were exposed to multiple procedures on a single day did not demonstrate high pain scores, despite frequent preventive or continuous analgesics ${ }^{10}$.

The authors concluded that pain assessment scores obtained through reassessments were poorly correlated with procedures or conditions associated with pain. Low pain scores through reassessment may not correlate with low pain exposure. Although 
JC supervision occurs, the results of this study suggest that documentation of pain reassessment may not directly facilitate the effective management of pain in NICUs ${ }^{10}$. Additional research is needed to explore scales, to reassess pain in the NICU to identify best practices, and to facilitate the management of the accumulated pain experience in premature infants.

A Swiss study with 120 ventilated NB and assessed for the presence of pain in procedures during 14 days showed that the NB were submitted to 38,626 procedures, an average of 22.9 procedures per patient, and $75.6 \%$ were painful ${ }^{11}$. The most frequent was the manipulation of CPAP nasal cannulas. The pain assessment occurred four to seven times a day, $99.2 \%$ of the patients received non-pharmacological and pharmacological measures of pain, and $70.8 \%$ received glucose as preventive analgesia for pain.

Regarding the use of corticosteroids in prenatal care, the same is indicated for pregnant women in labor, from 23 to 34 weeks of gestational age. One study assessed 463 pregnant women and their $514 \mathrm{NB}^{12}$. With regard to NB, they presented better Apgar scores at 1 and 5 minutes, less need for intervention in the delivery room and lower SNAPPE II (Score for Neonatal Acute Physiology with Perinatal Extension-II) for mortality and morbidity prediction in NICUs, were born in better clinical conditions, greater weight and gestational age. They also used less exogenous surfactant, and the NB remained shorter on mechanical ventilation and oxygen therapy.

However, it was associated with an increase in neonatal sepsis because the NB whose mothers received antenatal corticosteroids had a higher incidence of positive blood cultures and greater use of antibiotics and necrotizing enterocolitis. Investigations about antenatal treatment and the risk of infection are conflicting. Venipuncture is a painful procedure often performed in a NICU. Some authors have analyzed the efficacy of snoring PTNB for venipuncture. It was a study composed of $42 \mathrm{NB}, 21$ in the control group, and 21 in the treatment. When submitted to venipuncture, the pain was assessed with the Premature Infant Pain Profile Scale. In the treatment group, the NB were snored before the puncture, and the pain was significantly lower $(p<0.05)^{13}$.

A study of 38 PTNB of very low weight at Hermann Children's Hospital in Texas submitted to radial venous puncture for blood collection and/or calcaneal puncture were assessed for cardiac variability in response to pain stimuli ${ }^{14}$. They found a change in heart rate variability during procedures, coupled with evidence that a low-frequency response improved with advancing corrected gestational age.

Regarding cortisol, a hormone that assesses stress, a review of the integrative literature that analyzed 16 articles showed that the examination of retinopathy and the heel puncture provoked an increase in salivary cortisol level ${ }^{15}$. However, measures with music, prone position, and the use of the same crib between the twins reduced the level of salivary cortisol. The difficulties reported refer to the low rate of saliva sampling, and because they did not use control groups.

The assessment of salivary cortisol concentration is a precise method to indicate neonatal stress ${ }^{16}$. The use of glucocorticoids in prenatal care, such as betamethasone, interferes with the re- sponse to stress due to suppression of the adrenal gland. NB with a weight between 1,500 and $2,500 \mathrm{~g}$ showed a more intense reaction to stress, with mean salivary cortisol of $6,650.0 \pm 2,660.0 \mathrm{ng} /$ $\mathrm{dL}$. The authors state that the intense reaction of the NB to stress is detrimental to several physiological, functional, and structural systems in the short and long period.

PTNB, especially those of 24-32 weeks, undergo repeated painful procedures during a period of rapid brain development and stress system programming. They have nociceptive circuits to perceive pain; however, their sensory systems are immature so that an imbalance of excitatory versus inhibitory processes can lead to increased nociceptive signaling in the central nervous system ${ }^{17}$. Also, specific cells in the central nervous system of PTNB are particularly vulnerable to excitotoxicity, oxidative stress, and inflammation. Thus, increased exposure to stress related to neonatal pain has been associated with altered brain microstructure, levels of stress hormone, and changes in cognitive, motor, and behavioral development ${ }^{17}$. Therefore, it is vital that pain-related stress in PTNB is accurately identified, adequately managed, and that pain management strategies are assessed and performed for short- and long-term protective effects.

One study longitudinally examined gestational age and developmental differences in the self-regulating abilities of preterm infants in response to a painful stressor, as well as the associations between behavioral and cardiovascular responses ${ }^{18}$. Heel puncture blood samples from children 28 to 31 and from 32 to 34 weeks of gestational age at birth were assessed. Both groups presented behavioral and cardiovascular indications of stress in response to the blood draw. However, the NB at gestational ages more extreme (28-31 weeks) were more physiologically reactive. In this sense, the greater vulnerability to the stress of premature infants of 28-31 weeks compared to those of 32-34 weeks of gestation and the implications of this subsequent development are discussed.

Early life stress may alter the function of the hypothalamic axis (HPA) and the adrenal gland ${ }^{19}$. Differences in cortisol levels were found in PTNB exposed to procedural stress during neonatal intensive care compared with full-term NB, but only a few studies investigated whether the HPA axis alteration persists with child growth.

In addition, there is a lack of knowledge about what can contribute to these alterations in cortisol. In this context, a prospective cohort study examined salivary cortisol profiles in response to the stress of cognitive assessment as well as the diurnal rhythm of cortisol in children $(\mathrm{n}=129)$ born at different levels of prematurity (24-32 weeks gestation), term (38-41 weeks of gestation), and at 7 years of age ${ }^{19}$.

The authors demonstrated that cortisol profiles were similar in preterm and term $\mathrm{NB}$, although preterms presented higher cortisol at bedtime compared to full-term infants. Importantly, in the preterm group, greater stress related to procedural neonatal pain was associated with higher levels of cortisol on the day of study $(\mathrm{p}=0.044)$ and lower daytime cortisol at home $(\mathrm{p}=0.023)$, with effects observed mainly in boys. Also, attention deficit, negativity, and neuropsychological problems were associated with the cortisol response in the cognitive assessment in preterm $\mathrm{NB}^{19}$. 
Thus, pain and stress may contribute to the alteration of HPA axis function to school age in preterm infants, and gender may be an important factor. Early postnatal exposure to invasive procedures is stressful, especially when repeated several times a day during a period of immaturity.

\section{CONCLUSION}

The repeated venipuncture procedure intensified pain and altered cortisol. Upper limbs were more sensitive to pain reactions than lower limbs.

\section{REFERENCES}

1. Jeong IS, Park SM, Lee JM, Choi YJ, Lee J. Perceptions on pain management among Korean nurses in neonatal intensive care units. Asian Nur Res. 2014;8(4):261-6.

2. Taddio A, Katz J. Pain, opioid tolerance and sensitisation to nociception in the neonate. Best Pract Res Clin Anaesthesiol. 2004;18(2):291-302.

3. Prevention and management of procedural pain in the neonate: An Update. Pediatrics. 2016;137(2):e20154271.

4. Hingre RV, Gross SJ, Hingre KS, Mayes DM, Richman RA. Adrenal steroidogenesis in very low birthweight preterm infants. J Clin Endocrinol Metab. 1994;78(2):266-70.

5. Gordon BA, Fletcher MA. Neonatology and pathophysiology management of the newborn. $1^{\text {th }}$ ed. Philadelphia: Lippincott Wiliams and Wilkins; 1999

6. Jett PL, Samuels MH, McDaniel PA, Benda GI, Lafranchi SH, Reynolds JW, et al. Variability of plasma cortisol levels in extremely low birth weight infants. J Clin Endocrinol Metab. 1997;82(9):2921-5.
7. Newnham CA, Inder TE, Milgrom J. Measuring preterm cumulative stressors within the NICU: The Neonatal Infant Stressor Scale. Early Hum Dev. 2009;85(9):549-55.

8. Brasil. Resoluçāo CNS No 466 - Ministério da Saúde. [citado em 2017 jan. 06]. Disponível em: http://bvsms.saude.gov.br/bvs/saudelegis/cns/2013/res0466_12_12_2012.html.

9. Anand JJ, Hall RW. Pharmacological therapy for analgesia and sedation in the newborn. Arch Dis Child Fetal Neonatal Ed. 2006;91(6):F448-53.

10. Rohan AJ. The utility of pain scores obtained during 'regular reassessment process' in premature infants in the NICU. J Perinatol. 2014;34(7):532-7.

11. Cignacco E, Hamers J, van Lingen RA, Stoffeld L, Büchi S, Müller R, et al Neonatal procedural pain exposure and pain management in ventilated preterm infants during the first 14 days of life. Swiss Med Wkly. 2009;139(15):226-32.

12. Duarte JL. [Antenatal corticosteroid use and clinical evolution of preterm newborn infants]. J Pediatr. 2004;80(6):529-30; autor reply 530. Portuguese.

13. Lopez O, Subramanian P, Rahmat N, Theam LC, Chinna K, Rosli R. The effect of facilitated tucking on procedural pain control among premature babies. J Clin Nurs. 2015;24(1-2):183-91.

14. Padhye NS, Williams AL, Khattak AZ, Lasky RE. Heart rate variability in response to pain stimulus in VLBW infants followed longitudinally during NICU stay. Dev Psychobiol. 2009;51(8):638-49.

15. Mörelius E, He HG, Shorey S. Salivary cortisol reactivity in preterm infants in neonatal intensive care: an integrative review. Int J Environ Res Public Health. 2016;13(3): pii: E337.

16. Cabral DM, Antonini SR, Custódio RJ, Martinelli CE Jr, da Silva CA. Measurement of salivary cortisol as a marker of stress in newborns in a neonatal intensive care unit. Horm Res Paediatr. 2013;79(6):373-8.

17. Vinall J, Grunau RE. Impact of repeated procedural pain-related stress in infants born very preterm. Pediatr Res. 2014;75(5):584-7.

18. Lucas-Thompson R, Townsend EL, Gunnar MR, Georgieff MK, Guiang SF, Ciffuentes RF, et al. Developmental changes in the responses of preterm infants to a painful stressor. Infant Behav Dev. 2008;31(4):614-23.

19. Brummelte S, Chau CM, Cepeda IL, Degenhardt A, Weinberg J, Synnes AR, et al Cortisol levels in former preterm children at school age are predicted by neonatal procedural pain-related stress. Psychoneuroendocrinology. 2015;51:151-63. 